\title{
The lived experience of neophyte nursing instructors: mentorship and its role in their development
}

\author{
Lorelli S Nowell \\ Faculty of Nursing, University \\ of Calgary, Calgary, AB, Canada
}

This article was published in the following Dove Press journal:

Nursing: Research and Reviews

20 October 2014

Number of times this article has been viewed
Abstract: Numerous studies have identified the need for the mentorship of nursing instructors, yet there is a gap in literature identifying outcomes of successful mentorship programs. The purpose of this phenomenological inquiry was to uncover the lived experience of neophyte nursing instructors and the essence of the phenomenon of mentorship. Data were collected through individual interviews with six neophyte nursing instructors. Interviews were audio-taped and transcribed verbatim. Data were analyzed using a phenomenological procedural process. Four themes emerged: 1) what neophyte nurse educators want in a mentor, 2) identifying a new role, 3) mentorship experiences, and 4) becoming proficient as an instructor and mentor. This inquiry provides preliminary evidence-based knowledge for designing and implementing a mentorship program that is grounded in sound education principles, theory, and research.

Keywords: nursing education, mentoring, qualitative study, nursing faculty

\section{Introduction}

The current nursing shortage is demanding both nursing education programs and clinical agencies to expand the number of nursing instructors who are able to promote undergraduate student learning of nursing practice knowledge. ${ }^{1}$ Nursing education administrators are increasingly aware that current nursing instructors are often not prepared to teach in both classroom and clinical settings, resulting in a greater need for nursing instructors to teach in a clinical setting. Consequently, instructors who lack the necessary knowledge base to fulfill the educational role may be hired. ${ }^{2,3}$ It is imperative, then, that efforts from university administrators focus on attracting and retaining nursing instructors through supportive relationships and processes. ${ }^{4}$

Mentoring relationships and processes can improve novice nursing instructor development through deliberate and planned activities. ${ }^{1,5}$ Although confusion still exists in practice regarding the nature, definitions, and role of mentorship within nursing and across the broader literature, ${ }^{6,7}$ mentoring generally occurs, in professional nursing, when an experienced and knowledgeable registered nurse supports, assists, facilitates, and guides a novice working in an unfamiliar setting. The aim of mentoring is to support the mentee in developing the necessary skills to become a competent and knowledgeable practitioner. ${ }^{7,8}$

Mentoring relationships occur across a range of nursing contexts and are shown to have multiple, positive personal and professional outcomes. ${ }^{9}$ These nurturing relationships are intended to be developmental and empowering in which mutual sharing, learning, and growth occurs in an atmosphere of respect, collegiality, and affirmation. ${ }^{10}$ Mentoring relationships should exist in an environment that fosters the support of
Correspondence: Lorelli S Nowel Faculty of Nursing, University of Calgary, Professional Faculties Building

2500 University Drive NW,

Calgary, AB, Canada T2N IN4

Tel + I 4036209822

Fax +14032108101

Email Inowell@ucalgary.ca 
neophytes as they develop new skills and knowledge. These relationships ought to encourage inquiry and critical thinking, stimulate ideas and creativity, and awaken and challenge abilities to achieve future goals. ${ }^{11}$

Mentoring relationships can occur as highly structured formal programs of support and development that incorporate deliberate matching of experts with novices and the influence of organization requirements. ${ }^{9}$ In a formal mentoring program, the mentor is assigned to provide guidance to a new faculty member. Alternatively, mentoring may occur as informal learning alliances between people naturally drawn to each other and who unofficially set the nature and terms of their relationship. ${ }^{9}$ Informal mentoring relationships evolve spontaneously and are usually based on a good match between the mentor and the mentee. ${ }^{12,13}$

Within nursing education, mentoring fosters professional and educational development in the practice environment intensively over an extended period. The provision of ongoing guidance and support to instructors facilitates teaching skill development of novice nursing instructors. ${ }^{14}$ Benefits attributed to mentoring relationships include personal and professional learning and growth; inspiration for life changes; skill development; attainment of professional goals and career progression; and confidence, creativity, and fulfillment of potential. ${ }^{15}$ Firtko et al ${ }^{6}$ also suggest that mentoring helps neophyte instructors and their mentors grow and mature their professional selves.

Relevant across the entire career continuum of nursing instructors, mentorship may encompass orientation to the nursing instructor role, socialization to the academic community, developing teaching, and facilitating growth of future leaders in nursing and nursing education. ${ }^{16}$ Unique rewards are brought to the profession of nursing through mentorship such as affirming existing professional knowledge while facilitating role modeling, integrating theory and clinical practice, and contributing to future development of the profession. ${ }^{17}$ Mentoring is a means to sustain values and beliefs of the nursing profession, while ensuring continuity and quality leadership. ${ }^{9}$

Although numerous research studies have identified the need for mentorship of nursing instructors, there is a gap in research identifying how mentorship influences instructor development. In order to sufficiently prepare and support clinicians as they become instructors, further research is needed to discover how mentorship plays a role in developing the skills and knowledge to adequately fulfill the nursing instructor role. The purpose of this phenomenological inquiry is to create a description and understanding of the lived experience of mentorship and to understand its essential structure concerning the development of neophyte nursing instructors.

\section{Methods Design}

A phenomenological approach was used to explore the lived experience of mentored neophyte nursing instructors. Colaizzi's ${ }^{18}$ methodological framework guided the collection and analysis of the data. Phenomenological inquiry is an appropriate method for exploring the lived experiences and phenomenon presented in the everyday world of nursing. ${ }^{19}$ Mentorship is a phenomenon that has become important in current nursing practice.

\section{Participants}

Purposive sampling was used to select neophyte nursing instructors who: 1) were baccalaureate-prepared registered nurses; 2) had under 1 year of experience teaching undergraduate baccalaureate nursing students in a nursing practice setting; 3) were a resident of Calgary; and 4) were mentored by an instructor with at least 5 years' experience teaching undergraduate nursing students in a nursing practice setting. No standard preparation was provided to the mentors. Being mentored was defined as having an experienced and knowledgeable nursing instructor supporting, assisting, facilitating, and guiding the neophyte nursing instructor in the development of necessary skills to become a competent and knowledgeable nursing instructor.

\section{Data collection}

The author conducted individual in-depth interviews over 2 months using a semistructured interview guide (Table 1). Participants were informed that the research was being conducted as part of the author's Master of Nursing thesis. Interviews were conducted individually in private workplaces at the university where confidentiality and privacy could be maintained. Interviews lasted 60-90 minutes and were

\section{Table I Qualitative interview guide}

I. Can you tell me about any experience you have had as a mentor or mentee?

2. What does mentorship or mentoring mean to you?

3. Can you recall your thoughts and feelings when you first started in your role as a nursing instructor?

4. How has mentorship played a role in your development as a nursing instructor?

5. How might new nursing instructors be better prepared and supported as they transition into their new role?

6. Are there any questions that you thought I might ask that I didn't? 
audio-taped and transcribed verbatim. Within transcripts, all names and organizations were replaced with pseudonyms. Field notes were made before and after each interview, as part of the author's reflexive journal. All transcripts were returned to the participants for comment and to ensure accuracy.

\section{Data analysis}

Colaizzi ${ }^{18}$ sets forth a phenomenological procedure to unveil the meaning of participants lived experience through their responses to interview questions. To establish authenticity and trustworthiness of the research and ensure the line of thinking and interpretation was clear to the readers and true to the data, the supervisory committee double-checked the analysis during each step of this procedural process:

1. Interviews transcripts were read repeatedly to gain an understanding of the participant's experiences with mentorship.

2. After reviewing each transcript, significant statements relating to experience under research were extracted. These statements were highlighted and then cut from the appropriate transcript and pasted into a separate document while retaining the transcript, page, and line numbers. Table 2 illustrates how the significant statements were identified, highlighted, and then extracted.

3. For every significant statement extracted, meanings were formulated based on the participant's narratives. Each significant statement relating to the description and experience of mentorship was considered carefully to determine the meaning of mentorship. As formulated meanings were developed, the transcripts were read again to confirm the contextual meaning was not lost. Table 3 provides an example of how significant statements were interpreted into formulated meanings to describe the phenomenon of mentorship.

4. Meanings were organized into clusters of themes. The formulated meanings were arranged into theme clusters and then into emergent themes of the phenomenon of mentorship. Table 4 provides an example of the interpretive process for the emergent theme of "mentorship experience".

5. Themes were used to describe the phenomenon of mentorship. Emergent themes, theme clusters, and formulated meanings were incorporated into a descrip-

Table 2 Example of how significant statements were identified, highlighted, and extracted

46. Well for me, um mentorship would be a mentor a person I look up to and want to learn off, and, em, who has much more experience and greater stories than what I have. And someone I can get guidance from

Note: The number 46 represents the appropriate line in the transcript. tion to create the overall structure that contains all of the elements of the experience of mentorship.

6. Descriptions were returned to the participants to confirm validity. All six participants agreed that the essential structure of mentorship accurately represented their experiences.

7. Any new relevant data acquired from the participant's validation was incorporated into the final description.

\section{Ethical considerations}

Ethical approval was gained from the University of Calgary Conjoint Faculties Research Ethics Board. Prior to conducting interviews and once privacy was established, a written and signed consent was gathered.

\section{Findings}

All potential participants $(n=13)$ were identified by a clinical teaching coordinator and invited to contact the researcher if they wished to participate in the study. Participants did not receive any compensation for participating in the study. Overall, six instructors participated in the study, including five females and one male. Their age ranged from midtwenties to early fifties, and their clinical nursing experience ranged from 4 to over 30 years.

To appreciate the uniqueness of the nursing instructors who participated in this inquiry, each will be briefly introduced. Sandra has worked as a nurse for less than 5 years with a clinical focus in general surgery. She chose to pursue becoming a nursing instructor because as a student she had wonderful instructors and wanted to pass on that type of experience to other students. Kelly is a fairly recent graduate who quickly moved into an educator position in long-term care. As a result, Kelly developed a yearning to teach undergraduate nursing students. Jessica has a number of years of clinical nursing practice at an acute medical unit. She has trained and precepted a number of undergraduate nursing students prior to taking on the role of nursing instructor. Doug is the only male nursing instructor interviewed in this study. His four years of clinical nursing experience have been focused on pediatrics. Doug decided to pursue becoming a nursing instructor after observing other pediatric nursing instructors doing a disservice to undergraduate students in their clinical nursing placements. Mary has several years of clinical nursing practice focused in community nursing and lactation consulting. She chose to take on the role of nursing instructor as she saw it as a valuable opportunity to challenge her current nursing practice. Barbara has the most clinical nursing experience of the interviewed nursing instructors, 
Table 3 Process of creating formulated meanings from significant statements

\begin{tabular}{|c|c|}
\hline Significant statements & Formulated meanings \\
\hline$(5,8)$ Definitely preparing to teach and being comfortable in front & $(5,8)$ Challenges of being a neophyte instructor include preparation, \\
\hline of my students, looking like I knew what I was talking about & being comfortable teaching, and lack of confidence. These challenges \\
\hline were for me the biggest struggle and l've found now that l've taught & resolve over time with experience. \\
\hline \multicolumn{2}{|l|}{ one or two courses I feel ... I still have that initial ... I think everybody } \\
\hline \multicolumn{2}{|l|}{ has that initial nervousness when approaching their students } \\
\hline \multicolumn{2}{|l|}{ but the confidence comes. } \\
\hline$(\mathrm{I}, 48)$ They (mentors) are people who have much more experience, & $(I, 48)$ Mentors are chosen for their experience and approachability \\
\hline and I have observed how they practice and I admire them and their & and are admired by their mentees. \\
\hline \multicolumn{2}{|l|}{ way of practicing nursing, and they are people who are approachable. } \\
\hline$(3,165)[\ldots]$ and we do our labs together so I really feel those & $(3,165)$ Co-teaching with a mentor provides a supportive relationship \\
\hline first couple of labs that I, I really liked having him there as kind & to gain valuable skills in the role of nursing practice instructor \\
\hline of a mentor to say this is what I do ... I knew what to focus & and to lessen anxiety about the new role. \\
\hline \multicolumn{2}{|l|}{ on but it was my first time ever teaching and to teach a three hour } \\
\hline \multicolumn{2}{|l|}{ lab you know is kind of overwhelming to somebody who's never } \\
\hline \multicolumn{2}{|l|}{ taught before ... it was really great to have him there so he kind } \\
\hline \multicolumn{2}{|l|}{ of ran the first lab and I just kind of jumped in and that sort of stuff } \\
\hline and then as I went every week we did the same thing. & \\
\hline
\end{tabular}

Note: Figures in brackets denote the participant number, and the appropriate line in the transcript (ie $(5,8)=$ participant 5 , line 8$)$.

having graduated from her nursing program over 30 years ago. Barbara has a strong clinical nursing background with a focus in mental health. She expressed that teaching was always something she desired to do and that she had taught a great deal in a number of her other nursing roles.

Four theme clusters emerged from the data (Table 5): 1) what neophyte nurse educators want in a mentor, 2) identifying a new role, 3) mentorship experiences, and 4) becoming proficient as an instructor and mentor.

\section{What neophyte nurse educators want in a mentor}

Relationships

Participants regarded having an effective relationship with their mentors as vital to making the mentorship work. Doug spoke about how having a personal relationship with his mentors eased his job orientation:
[...] that relationship with the faculty and the staff members made it a easier to move around and figure out who we had to talk to, to get stuff.

Mary also articulated how a previous relationship with a colleague who was an experienced instructor opened the doors for mentorship to occur and created a comfortable environment for asking questions:

We taught together and so I asked her, she sat down and told me everything I needed to know ... I asked her a bunch of questions.

Jessica spoke about how her mentor accepted the variances in their teaching practices:

[...] there are some things that I would definitely do different, you know, but he's accepting to that so that's why it works.

Table 4 Illustrating the emergence of themes from theme clusters and formulated meanings

\begin{tabular}{lll}
\hline Formulated meanings & Theme clusters & Emergent theme \\
\hline$(I, 26)$ The mentorship experience was helpful to observe teaching. & Mentorship experience \\
$\begin{array}{l}(I, I I 0) \text { Mentorship provides a supportive learning environment to demonstrate the practice } \\
\text { of clinical nursing education. }\end{array}$ & Observation \\
$(2, I 0)$ It is valuable for new instructors to have a mentor who they can observe in practice. & Observation \\
$(3,354)$ The experiences of watching a mentor teach is more effective than reading & Observation \\
about how to teach. & \\
$(5,18)$ Senior mentors can provide teaching pointers, lesson plans, direction, and focus. & Observation \\
$(I, 26)$ The mentorship experience was helpful to provide guidance & Hands-on practice \\
on how to adapt similar practice. & \\
$(2,2)$ Mentorship can provide a more hands-on learning experience. & Hands-on practice \\
$(3,93)$ The instructor guides provide mentorship to new instructors. & Written mentorship \\
$(3, I I I)$ Having a checklist to ensure all information has been provided would be helpful. & Written mentorship \\
\hline
\end{tabular}

Note: Figures in brackets denote the participant number, and the appropriate line in the transcript (ie, $(\mathrm{I}, 26)=$ participant I, line 26). 
Table 5 Themes and subthemes

\begin{tabular}{ll}
\hline What neophyte nurse educators & Relationships \\
want in a mentor & Willingness to be a mentor \\
& Similarities \\
& Differences \\
& Feedback \\
& Ability to allow mentee to grow \\
& into confident instructors \\
& Moving from expert to novice \\
& Facing the unknown \\
Identifying a new role & Searching for information \\
& Looking to those with experience \\
& Opening the line of communication \\
Mentorship experiences & Someone to answer questions \\
& Observation \\
Written mentorship \\
as an instructor and mentor & Co-teaching \\
& Peer mentorship \\
&
\end{tabular}

\section{Willingness to be a mentor}

A mentor who is a willing participant and open to being observed by another instructor in practice offered a valuable learning opportunity. Kelly offered her opinion on what she wants in a mentor:

[...] willing to be a mentor, and willing to have someone shadow and who is willing to explain kind of what is going on. You don't want to shadow someone who is not going to speak to all day or acknowledge your existence.

A mentor was seen as someone with experience who willingly invites neophyte instructors to learn from them, the role of which was articulated as providing guidance to those with less experience. Participants believed that mentors should be chosen for their experience and approachability. Sandra expressed how she has self-selected mentors to help guide her practice:

[Mentors] are people who have much more experience, and I have observed how they practice and I admire them and there way of practicing nursing, and they are people who are approachable.

\section{Similarities}

Mentors with similar work roles as neophyte nursing instructors were sought after to compare and critique their practice. Mentors who practiced in a different environment than participants could not answer pertinent questions. Sandra voiced why she would want a mentor with similar work experience:

I want to talk to someone who has been instructing for a while so that I can see how she does things and maybe compare notes. And see where I can learn and fine tune what I am doing.

Kelly expressed similar desires:

I think that as long as you are following a very strong, senior sessional instructor, maybe on a similar unit as to what you are going to be on or teaching a similar class as to what you are going to be on. I think that would be very helpful.

\section{Differences}

Despite agreeing or disagreeing on teaching styles, several participants articulated that having a mentor provides a richer learning experience for the students. Working with mentors with different teaching styles was seen as part of professional practice and can be beneficial for mentors and mentees. Jessica expressed how having a varied background from her mentor allowed a "richer opportunity" for student learning:

His surgical background and his mental health background has brought in a lot because I've only been in internal medicine, which is great that's where we are, but he adds in his experiences which I think is helpful too to come from a different field.

Mary spoke about the differences between herself and her mentor:

[...] my team teacher and I are stark opposites. She is so structured, has timelines for everything and I'm like, if this takes an hour then it takes an hour, if it takes half an hour that's fine we'll move on to something else. Working with people that you're not entirely compatible with was such a beneficial learning experience for me.

\section{Feedback}

A mentor who provided feedback allowed the participants to double check that they were on the right track. Mary suggested that feedback from mentors can improve teaching practice and keep teaching styles current and fresh for "seasoned instructors, as well as new instructors":

To have someone to help you and give you feedback, give you new ideas to improve your practice ... and it's a professional responsibility too to reflect on your practice ... and improve it based on feedback. I mean you can take it or leave it, the feedback, but it's always good to hear it, right?

Doug articulated his need to have a respectful relationship with his mentors and to have an appreciation for their knowledge and experience when receiving feedback: 
I respect their knowledge. If we get along personally then it's a whole lot easier to take the constructive feedback.

\section{Ability to allow mentees to grow into confident instructors}

An available mentor allowed participants to try things out for themselves and develop confidence in their teaching, while knowing someone was there to support and guide them if needed. Jessica spoke about her experience of feeling supported, and gaining confidence to implement required teaching tasks independently:

[...] she was pretty good at saying, "I will deal with anything that you can't deal with, you can always come to me for anything but if you feel you can deal with it yourself then please go ahead", so giving you the okay to say you don't have to come to me about every little tiny thing.

\section{Identifying a new role Moving from expert to novice}

Adjusting from the role of expert nurse clinician to a novice instructor was difficult for participants. They faced many new roles and unfamiliar responsibilities, often trying to figure out how to perform these responsibilities independently. Kelly described her initial struggles in her new role:

Never had I had eight students and tried to manage eight students ... I never had taught a lab before so you had to try and figure out how to do that as well.

Although challenged with this adjustment, this was overcome by having supportive people to turn to for advice and with increasing experience teaching. Doug identified that he "had a hard time adjusting to coming into nursing starting at the bottom again and people saw that and were able to give me suggestions on how to make that work". Mary described how she resolved her challenges with more teaching experience over time and through that gained confidence:

I think everybody has that initial nervousness when approaching their students but the confidence comes with time ... I've learned the more prepared you are the better the class will go.

\section{Facing the unknown}

Participants were new to their role and faced some uncertainty. Some expressed the overwhelming feeling of facing the unknown and "trying to figure it out all as you go along" independently. Kelly described the feelings she had during her first clinical teaching experience:

I found the first semester very difficult to adapt, not knowing what to do, not knowing how to write evaluations, not knowing how to write anecdotal notes, not really knowing how to interact with students properly, not knowing how to do post conferences.

Sandra also spoke of how she tackled an unknown aspect in her new nursing instructor role:

I kind of winged it ... I was never told, I guess it is kind of understood ... but I actually didn't know .... Now I realize that is the way to do it but no one told me.

\section{Searching for information}

When starting in their new role, a lack of answers caused stress and anxiety in participants. Sandra described her feelings of not having clear answers about the level of her students:

I found it a little hard to know what they were supposed to know from before and what they were supposed to wait and not do, because they learn later. I found that there was a bit of haziness around that, it was not very clear cut.

When questions arose, finding guidance was difficult and there was uncertainty about who to ask. Vague answers to questions were a source of frustration for instructors who desired to do their job correctly. The lack of a consistent person to ask questions was both overwhelming and time consuming for several participants, including Mary who expressed her concerns about not knowing where to get her questions answered:

[...] where you're missing information or where you can get that information and it can be overwhelming ... where are the resources, how does the class work?

\section{Looking to those with experience}

Participants often looked to those with similar role experience for information and guidance and sought out experienced instructors to learn from their example. Sandra expressed how she chose who to call when she had questions:

She teaches the same course and she's taught it for like ten years ... I wanted to ask her to show me some of her examples so that I could see whether I'm doing something different or I can learn from that.

Several participants found that experienced instructors wanted to share their knowledge to support the new instructors. Doug spoke of his experience: 
I was lucky that I had a lot of decent and good people working with me that were able to kind of take me under their wings, "this is how we do these labs and you know this is what you are going to talk about and stuff", so that was good.

Mary also had a similar experience with seasoned instructors stating:

there were a couple of instructors that were really, really helpful, there are some people that really just stepped up and voluntarily helped.

Mary went on to explain that she knew other neophyte nursing instructors were finding this support beneficial as well:

I'm hearing from other people as well that having those people that are willing to be mentors make the biggest difference as opposed to trying to figure them out yourself.

\section{Mentorship experiences Opening the lines of communication}

For fear of intruding on their time, participants hesitated in contacting others with questions. Mary identified being nervous to ask people questions who had not already opened the lines of communication

I would be nervous to approach people that didn't volunteer the information, that I was inconveniencing them and some people are often more willing to help you than others.

There was an underlying desire to have a mentor assigned. The idea of a mentor contacting the neophyte instructor allowed the lines of communication to be opened and provided an opportunity to ask questions about the unknown, without feeling as though they were intruding on the mentor's time. Jessica spoke about how the regular, nonpatronizing contact from her mentors, "lots of emails regularly with suggestions", allowed her to more easily seek information when needed.

It was just very nice, it was like FYI don't forget this for next week, make sure this week you talk to them about next week and answering some general questions.

\section{Someone to answer questions}

All participants agreed that it was beneficial to have someone able to answer questions and provide guidance about how to perform required job tasks. Kelly articulated that her initial teaching experience:
[...] went really well as I did have that mentor who worked opposite shifts with me who I could kind of rely on and ask questions.

Mary acknowledged that her questions had evolved with experience:

[...] my questions are more focused on the different learning needs of the students ... how do I take this information and deliver it to the very different learning needs that I'm seeing with my students and not lose the ones that are, not higher up, but taking it much easier and don't need it laid out so simply for them.

\section{Observation}

Mentorship provided the participants with a supportive learning environment to observe the practice of clinical nursing education. When describing her observation day, Sandra warmly recalled what she had experienced:

She told me what she had given the students on the first day and the information and expectations and stuff like that and then she took me around to show me how she sent people to the OR, and then post conference ... [that] was helpful and guided me and set off to adapt similar things for my group.

The observation experiences helped participants gain a greater understanding of what clinical teaching might look like and how they could incorporate what they observed into their own teaching practice. Jessica expressed how her experience watching her mentor teach was more effective than reading about how to teach:

$[\ldots]$ the experience of just watching Mike, when they (the students) started asking questions, him not answering and without necessarily giving them the answers, how can you ask them questions and I don't think you can get that down on paper, I think it has to be from somebody who's just teaching and going with the flow.

Observing more experienced instructors interact with students and organize their teaching assignments provided participants with a greater understanding of what the job role entails. Creating this supportive learning environment to observe clinical nursing education practice was viewed as beneficial for all participants.

\section{Written mentorship}

Written mentorship, in the form of instructor guides and handbooks, provided crucial direction and clarification when 
planning lessons. Jessica spoke about how she found the instructor guides helpful:

Sarah handed out a binder that was really good. It had all the weeks of what they suggested for on campus and off campus focuses. What to do, an instructor guide kind of thing. So, going through that really helped me out.

Mary spoke about how more experienced instructors were willing to share written handbooks and information they had gathered over the years to help guide and support the neophyte nursing instructors in their new role:

[...] that really helped me to give me some structure as far as what we were supposed to be talking about and how to address the points that we wanted to address with the curriculum. ... If I didn't have that information that Natasha sent me, I would have been floundering.

\section{Co-teaching}

Pairing a novice with an experienced instructor provided a supportive relationship to gain valuable skills in the role of instructor and diminished anxiety about the new role. Jessica spoke about her initial experience of co-teaching with a more practiced instructor:

I really liked having him there as kind of a mentor to say, "this is what I do" ... if I didn't have that experience that would have been very overwhelming ... when they're designing the labs [they should] make sure that they have somebody who's new buddy them with somebody who has taught before.

Despite potentially different teaching styles, co-teaching also provided an opportunity for growth and learning for both the mentor and mentee. Jessica noted how she and her mentor had different teaching ideas and were able to learn from each other:

[...] we do different things in clinical. I feel that he's actually taking some of my suggestions or way of thinking and added it into his as well.

Mary saw her co-teaching experiences as a beneficial way for her to keep herself accountable and it encouraged her to put their best effort forward:

[Co-teaching] really makes you pull your boots up. You want to be looking like you know what you're doing so, and it just set me off on a really strong footstool to continue the rest of the semester.

\section{Peer mentorship}

Being a neophyte nursing instructor can be overwhelming, and nursing instructors can benefit from supporting one another to learn from each other's experiences. When struggling with an aspect of the nursing instructor role, many participants found it helpful to speak to others about how they have handled similar challenges. Doug spoke about his challenge in writing anecdotal notes:

I still have a hard time with anecdotal notes and that's ...

I mean I work on it and I talk to one of the other folks about ways to do it.

Mary also spoke about how informal peer mentoring occurred through simply teaching in the same area as another neophyte nursing instructor:

It sets up partnerships because we were working together so much now we feel comfortable deferring to each other throughout the semester, which is good.

Mentoring each other ensured that everyone was doing their job to the best of their ability and made it easier for everyone. Mary valued having team meeting with her peers:

[...] to socialize with the other instructors so you can create those relationships, ask questions from each other, say you know "this is what is happening to me what do you think about it, is this normal or what sort of strategies do you think can happen?"

\section{Becoming proficient as an instructor and mentor}

Mentoring often happened with increasing experience, sometimes occurring without even knowing it. Jessica voiced her experience of unknowingly becoming a mentor:

I'm not ready to be the mentor, but then realizing I've actually been doing it for quite a while without noticing it ... just the same way Karen was doing it with me.

As a result of this mentoring, Kelly and Mary articulated that they would happily mentor other neophyte instructors. Kelly said, "absolutely, I would. I like to mentor and teach", and Mary expressed her involvement in helping a neophyte instructor find a great mentor:

I know how new instructors feel and how lost they can be and important it is so, definitely I would be taking people under my wing. 


\section{Discussion}

This phenomenological study revealed that neophyte nursing instructors face the unknown as they move from expert clinician to novice instructor. Neophyte instructor's benefit from mentors with both similar and varied backgrounds and teaching styles, and a long-lasting relationship is preferred. They find themselves searching for information and often look to those with more experience for guidance. Mentorship helps open the lines of communication, answers questions, and translates theory into practice. Mentorship comes in many forms, and successful mentoring occurs when the mentoring relationship is respected and mentors are willing to take on the mentoring role. The feedback and support that mentors provide allows mentees to grow into confident instructors and encourages them to mentor the next generation of instructors.

When facing many new roles and unfamiliar tasks, neophyte instructors often attempted to perform these tasks independently. Hired as content and clinical experts, yet unfamiliar with the nursing instructor role, neophyte instructors are too often left to figure things out alone, making the transition to their new role even more difficult. ${ }^{20}$ While they bring current knowledge of clinical practice to the academic setting, these instructors sometimes lack the knowledge and skills required to excel in an academic setting. Bell-Scriber and Morton ${ }^{21}$ also suggest that instructors often have no prior training in teaching, learning, or orientation to the instructor role, and these underprepared instructors tend to teach as they were taught and learn on the job through trial and error. Without continuing support from seasoned instructors, neophyte instructors often draw on their practice experience and expertise to form a basis for developing their skills and expertise in teaching. ${ }^{22}$

Participants expressed a desire to have a mentor assigned to open the lines of communication and provide opportunities to ask questions without feeling as though they were intruding on the mentor's time. Peters and Boylston ${ }^{20}$ suggest that fostering collegial mentoring relationships is invaluable in promoting communication, connection, and caring among new nursing instructors. A mentor can support and guide neophyte instructors as they begin to translate teaching theory into their own teaching practice. ${ }^{6,23}$ Formal instruction in education, with informal guidance from a mentor can support neophyte instructors as they develop clinical teaching skills. ${ }^{5}$

Participants experienced various forms of mentorship, including observation, written mentorship, co-teaching, and peer mentorship. Mentorship provided the neophyte instructors with a supportive learning environment to observe the practice of clinical nursing education. From a teaching perspective, mentorship programs can enhance instructional abilities through observation. ${ }^{6,23}$ Informal guidance from an experienced instructor and formal instruction in education can support neophyte instructors as they develop clinical teaching skills. ${ }^{5}$ The co-teaching relationship also offers the opportunity for professional growth that comes from giving and getting feedback from a well-respected peer. Co-teaching supports the development of professionals who collaborate, problem solve, share resources and perspectives, and conceptualize teaching as a process of learning. ${ }^{24} \mathrm{Co}$-teaching the same subject matter to similar students offers instructors an opportunity to compare the effectiveness of varied strategies and methods of teaching, and engage in pedagogical discussions that rise above the particularities of a single lesson. ${ }^{24}$ When struggling with parts of the instructor role, participants found it helpful to speak to others about how they have handled similar challenges. Peer mentors may guide peers in acquiring new knowledge and skill competency through applying critical thinking; developing a sense of professional responsibility and accountability; advancing personal leadership and facilitation skills; and gaining insight into teacher role. ${ }^{25}$

Having an accepting mentor makes the mentorship relationship work. Participants characterized desirable mentors as those who had engaged in a personal relationship, who were willing to mentor and provide feedback, and supported growth into confident instructors. Mentoring encourages senior nurse educators to share their unique talents and skills with neophyte instructors, therefore promoting their professional growth. ${ }^{4}$ Bergstresser ${ }^{26}$ stresses the importance carefully matching mentors with mentees, as mentoring relationships are enhanced by similar interests and challenged by differences. Although participants in this study wanted mentors with similar work roles, differences in teaching style or professional practice were also seen as beneficial. Whether teaching styles aligned or not, having a mentor provided a richer student learning experience and opportunities to confront and explore various teaching styles.

Effective mentoring prepares mentees to become mentors themselves to the next generation of instructors. ${ }^{2}$ Participants described how becoming a mentor happened unknowingly over time and expressed that they would happily mentor other neophyte instructors - a process that may both reinforce and validate knowledge. When this type of atmosphere is fostered, 
the same guidance and care is possibly transferred to not only peers but also nursing students, the next generation of practicing nurses. ${ }^{11}$

The nursing profession is looking to mentoring as an effective approach to nurture the development of neophyte instructors. A mentorship program can provide professional and psychological support to instructors transitioning to a new role while supporting a connection to the institution, increasing satisfaction with their role and providing a sense of value for their work. Kelly ${ }^{2}$ argues that experienced nursing instructors can mentor novice instructors and provide instruction leading to success in the instructor role, and ultimately, the program and the profession of nursing. As the number of adjunct faculty positions continue to grow in response to the nursing faculty shortage, it is essential to support and retain these valuable resources. Well-prepared and successful instructors are critical to the achievement of nursing education programs. If mentorship programs are absent, the success and empowerment accompanied by successful mentorship will be difficult to achieve.

This study includes the insight from six participants from two institutions, limiting generalizability of findings. Due to the small sample size, it cannot be concluded that saturation was reached, which is a limitation and potential flaw in this study. The rich narrative descriptions that could be expanded through interviewing more neophyte nursing instructors from various educational institutions may further our understanding of how mentorship plays a role in their development. Though the sole focus of this paper is on the mentorship experiences of neophyte nursing instructors, additional research on both mentee and mentor experiences may provide greater insight into the role of mentorship in developing both experienced and neophyte nursing instructors.

\section{Conclusion}

Well-prepared and successful instructors are critical to the achievement of nursing education programs. This study offers greater appreciation and sensitivity to the struggles neophyte nursing instructors face and how mentorship facilitates the development of instructors who are needed to adequately fulfill the educator role. This inquiry provides preliminary evidence-based knowledge to inform the design and implementation of mentorship programs grounded in sound education principles, theory, and research.

\section{Disclosure}

The author reports no conflicts of interest in this work.

\section{References}

1. Smith JA, Zsohar H. Educational innovations. Essentials of neophyte mentorship in relation to the faculty shortage. JNurs Educ. 2007;46(4): 184-186.

2. Kelly RE. Engaging baccalaureate clinical faculty. Int J Nurs Educ Scholarsh. 2006;3(1):1-16.

3. Cangelosi PR, Crocker S, Sorrell JM. Expert to novice: clinicians learning new roles as clinical nurse educators. Nurs Educ Perspect. 2009;30(6):367-371.

4. Dunham-Taylor J, Lynn CW, Moore P, McDaniel S, Walker JK. What goes around comes around: improving faculty retention through more effective mentoring. J Prof Nurs. 2008;24(6):337-346.

5. Wilson CB, Brannan J, White A. A mentor-protégé program for new faculty, Part II: stories of mentors. J Nurs Educ. 2010;49(12):665-671.

6. Firtko A, Stewart R, Knox N. Understanding mentoring and preceptorship: clarifying the quagmire. Contemp Nurse. 2005;19:32.

7. van Eps MA, Cooke M, Creedy DK, Walker R. Student evaluations of a year-long mentorship program: a quality improvement initiative. Nurse Educ Today. 2006;26(6):519-524.

8. Saarikoski M, Marrow C, Abreu W, Riklikiene O, Özbicakçi S. Student nurses' experience of supervision and Mentorship in clinical practice: a cross cultural perspective. Nurse Educ Pract. 2007;7(6):407-415.

9. McCloughen A, O’Brien L, Jackson D. Esteemed connection: creating a mentoring relationship for nurse leadership. Nurs Inq. 2009;16(4): 326-336.

10. Vance C, Olson RK. The Mentor Connection in Nursing. New York: Springer Publishing Company; 1998.

11. Kanaskie ML. Mentoring - a staff retention tool. Crit Care Nurs Q. 2006;29(3):248-252.

12. Gazza EA, Shellenbarger T. Successful enculturation: strategies for retaining newly hired nursing faculty. Nurse Educ. 2005;30(6): $251-254$

13. Sawatzky J-AV, Enns CL. A mentoring needs assessment: validating mentorship in nursing education. J Prof Nurs. 2009;25(3):145-150.

14. Manning L, Neville S. Work-role transition: from staff nurse to clinical nurse educator. Nurs Prax NZ. 2009;25(2):41-53.

15. Morton-Cooper A, Palmer A. Mentoring, Preceptorship and Clinical Supervision. Vol 2nd. Oxford: Blackwell Science; 2000.

16. Schumacher G, Risco K, Conway A. The Schumacher Model: fostering scholarship and excellence in nursing and for recruiting and grooming new faculty. J Nurs Educ. 2008;47(12):571-575.

17. Cardwell P, Corkin D. Mentorship: the art and science. Paediatr Nurs. 2007;19(4):31-32.

18. Colaizzi PF. Psychological research as the phenomenologist views it. In: Valle RS, King M, editors. Existential Phenomenological Alternatives for Psychology. New York: Oxford University Press; 1978:58-62.

19. Speziale H, Carpenter D. Qualitative Research in Nursing: Advancing the Humanistic Imperative. Vol 4th. Philadelphia: Lippincott Williams \& Wilkins; 2007.

20. Peters MA, Boylston ME. Mentoring adjunct faculty: innovative solutions. Nurse Educ. 2006;31(2):61-64.

21. Bell-Scriber MJ, Morton AM. Clinical instruction: train the trainer. Nurse Educ. 2009;34(2):84-87.

22. Diekelmann N. Teacher talk: new pedagogies for nursing. Experienced practitioners as new faculty: new pedagogies and new possibilities. J Nurs Educ. 2004;43(3):101-103.

23. White A, Brannan J, Wilson CB. A mentor-protégé program for new faculty, part I: stories of protégés. J Nurs Educ. 2010;49(11):601-607.

24. Kohler-Evans P. Co-teaching: how to make this marriage work in front of the kids. Education. 2006;127:260-264.

25. Colvin JW, Ashman M. Roles, risks, and benefits of peer mentoring relationships in higher education. Mentor Tutor Partnership Learn. 2010;18(2):121-134.

26. Bergstresser PR. Academic mentoring. J Investig Dermatol. 2011; 131(2):273-274. 
Nursing: Research and Reviews

\section{Publish your work in this journal}

Nursing: Research and Reviews is an international, peer-reviewed, open access journal publishing original research, reports, reviews and commentaries on all aspects of nursing and patient care. These include patient education and counselling, ethics, management and organizational issues, diagnostics and prescribing, economics and

\section{Dovepress}

resource management, health outcomes, and improving patient safety in all settings. The manuscript management system is completely online and includes a very quick and fair peer-review system. Visit http://www.dovepress.com/testimonials.php to read real quotes from published authors.

Submit your manuscript here: http://www.dovepress.com/nursing-research-and-reviews-journal 